\title{
Anti-MUC16/MMAE Antibody-Drug Conjugate DMUC4064A
}

National Cancer Institute

\section{Source}

National Cancer Institute. Anti-MUC16/MMAE Antibody-Drug Conjugate DMUC4064A. NCI Thesaurus. Code C147031.

An antibody-drug conjug ate (ADC) composed of a monoclonal antibody against human mucin 16 (MUC16; cancer antigen 125; CA125; FLJ14303) conjug ated to monomethyl auristatin $\mathrm{E}(\mathrm{MMAE})$, an auristatin derivative and potent microtubule disrupting agent, with potential antineoplastic activity. Upon administration, anti-MUC16/MMAE ADC DMUC4064A binds to MUC16 located on the tumor cell surface. After internalization of the agent, the MMAE moiety is released and binds to tubulin and inhibits its polymerization, which results in G2/M phase arrest and apoptosis. MUC16, a member of the mucin family glycoproteins, is overexpressed in a variety of tumor cells and plays a key role in tumor cell proliferation. 